\title{
ANALISIS STABILITAS LERENG AKSES GERBANG SELATAN UNIVERSITAS LANCANG KUNING
}

\author{
Virgo Trisep Haris ${ }^{1}$, Fadrizal Lubis ${ }^{* 2}$, Winayati ${ }^{3}$ \\ Program Studi Teknik Sipil Universitas Lancang Kuning \\ Jalan Yos Sudarso Km. 8 Rumbai Pekanbaru \\ *Corresponding authors: fadrizal@unilak.ac.id
}

Received: 27 Agustus 2019, Accepted: 04 Oktober 2019

DOI: $10.31849 /$ siklus.v5i2.3178

\begin{abstract}
Abstrak
Areal Universitas Lancang Kuning Pekanbaru (Unilak) memiliki lahan yang berkontur. Jalan gerbang timur dan gerbang selatan berada pada kondisi berkontur yang cukup ekstrim (berlereng) di areal Universitas Lancang Kuning. Untuk bangunan yang berada atau dibangun pada daerah berkontur yang ekstrim akan rawan atau berpotensi mengalami longsor. Jalan gerbang timur dibangun bersamaan dengan pembangunan bangunan-bangunan pertama kompleks bangunan Universitas Lancang Kuning, yang dalam proses pembangunannya sudah menggunakan dinding penahan tanah untuk menjaga kesetabilan struktur jalan tersebut, sedangkan jalan gerbang selatan belum mendapatkan penanganan terhadap kemungkinan terjadinya bahaya longsor pada lereng jalan tersebut. Untuk mengetahui apakah dapat terjadi atau tidaknya potensi longsor pada lereng gerbang selatan, perlu dilakukan analisis kesetabilan pada lereng akses gerbang selatan tersebut Dari hasil hitungan terhadap penelitian yang dilakukan, didapat nilai faktor aman untuk kesetabilan lereng akses gerbang selatan Universitas Lancang Kuning adalah sebesar 0,91 (lebih kecil dari 1) yang berarti kondisi lereng akses gerbang selatan Universitas Lancang Kuning dalam keadaan tidak aman.
\end{abstract}

Kata Kunci : Lereng, longsor, stabilitas

\begin{abstract}
The area of Lancang Kuning University of Pekanbaru (Unilak) has contoured land. The east gate and the south gate are in quite extreme contour conditions (sloped) in the area of Lancang Kuning University. For buildings that are located or built in extreme contoured areas will be vulnerable or potentially experiencing landslides. The eastern gate was built in conjunction with the construction of the first buildings of the Lancang Kuning University building complex, which in the process of construction had used a retaining wall to maintain the stability of the road structure, while the south gate had not yet received a response to the possibility of a landslide hazard on the road slope. To find out whether or not a potential landslide can occur
\end{abstract}


on the south gate slope, it is necessary to analyze the stability on the south gate access slope. From the results of calculations on the research conducted, the safety factor value obtained for the stability of the southern gate access slope of Lancang Kuning University was 0.91 (smaller than 1), which means the condition of the southern gate access slope at Lancang Kuning University was unsafe.

Keywords: Slope, landslide, stability

\section{A. PENDAHULUAN}

Tanah yang buruk tidak dapat Universitas Lancang Kuning memiliki lima akses (jalan masuk) dengan dua akses utama, yaitu gerbang timur di jalan Yos Sudarso dan gerbang selatan di jalan Umban Sari. Akses lainnya untuk masuk dapat ke lokasi Universitas Lancang Kuning adalah melalui jalan Patria Sari kemudian melewati jalan disamping bangunan Fakultas Ilmu Administrasi dan Fakultas Teknik, serta dari jalan Yos Sudarso melalui lapangan Soft Ball menuju ke Fakultas Hukum.

Areal Universitas Lancang Kuning Pekanbaru (Unilak) memiliki lahan yang berkontur. Jalan gerbang timur dan gerbang selatan berada pada kondisi berkontur yang cukup ekstrim (berlereng) di areal Universitas Lancang Kuning. Untuk bangunan yang berada atau dibangun pada daerah berkontur yang ekstrim akan rawan atau berpotensi mengalami longsor.

Jalan gerbang timur dibangun bersamaan dengan pembangunan bangunan-bangunan pertama kompleks bangunan Universitas Lancang Kuning, yang dalam proses pembangunannya sudah menggunakan dinding penahan tanah untuk menjaga kesetabilan struktur jalan tersebut, sedangkan jalan gerbang selatan belum mendapatkan penanganan terhadap kemungkinan terjadinya bahaya longsor pada lereng jalan tersebut, terutama pada lereng sisi timur daerah sekitar hall olahraga Politeknik Caltex Riau sampai ke pos Waradipa Universitas Lancang Kuning
Untuk mengetahui apakah dapat terjadi atau tidaknya potensi longsor pada lereng gerbang selatan, perlu dilakukan analisis kesetabilan pada lereng akses gerbang selatan tersebut, dengan menggunakan data-data nilai kohesi tanah (c), sudut geser tanah (Ø) dan berat isi tanah $(\gamma)$ yang sudah didapat pada penelitian sebelumnya..

\section{B. TINJAUAN PUSTAKA}

\section{Kelongsoran Tanah}

Masalah kelongsoran tanah sering terjadi disebabkan keadaan geografi yang dibeberapa tempat memiliki curah hujan cukup tinggi dan daerah potensi gempa. Curah hujan yang tinggi dianggap sebagai faktor utama kelongsoran karena air dapat mengikis suatu lapisan pasir, melumasi batuan ataupun meningkatkan kadar air suatu lempung sehingga mengurangi kekuatan geser (Kusuma D, 2016).

Kemungkinan longsor akibat hujan masih harus dikaitkan dengan beberapa faktor antara lain topografi daerah setempat, struktur geologi, sifat kerembesan tanah dan morfologi perkembangannya. Permasalahan yang umumnya melatarbelakangi bencana tanah longsor adalah (Kusuma D, 2016):

a. Kemiringan lereng yang hampir tegak lurus akan berpengaruh terhadap stabilitas lereng. Adanya infrastruktur yang berdiri di atas lereng tidak mungkin dipindah sehingga lahan untuk membuat lereng sangat terbatas. 
b. Keadaan geografi yang memiliki curah hujan cukup tinggi yang meningkatkan kadar air pori sehingga mengurangi kekuatan geser.

c. Bertambahnya kadar air pori jika terjadi hujan lebat karena kurang berfungsinya kemiringan saluran drainase pada konstruksi tersebut yang mengakibatkan terhambatnya aliran air yang akan keluar sehingga tekanan air pori meningkat dan berpotensi mengakibatkan kelongsoran.

d. Di atas lokasi longsor telah berubah fungsi dari daerah hijau menjadi pemukiman yang menyebabkan berkurangnya daerah resapan air sehingga terjadi perubahan kandungan air tanah dalam rongga dan akan menurunkan stabilitas tanah.

\section{Kestabilan Lereng}

Pada prinsipnya, cara yang dipakai untuk menjadikan lereng supaya lebih aman (lebih mantap) dapat dibagi dalam dua golongan, yaitu

a. memperkecil gaya penggerak atau momen penggerak Gaya atau momen penggerak dapat diperkecil hanya dengan cara merobah bentuk lereng yang bersangkutan. Untuk itu ada dua cara :

1) Membuat lereng lebih datar, yaitu mengurangi sudut kemiringan.

2) Memperkecil ketinggian lereng.

b. Memperbesar gaya melawan atau momen melawan

Gaya melawan atau momen melawan dapat ditambah dengan beberapa cara, yang paling sering dipakai ialah sebagai berikut :

1) menggunakancounterweight, yaitu tanah timbunan pada kaki lereng.

2) mengurangi tegangan air pori di dalam lereng.
3) cara mekanis, yang dengan memasang tiang atau dengan membuat dinding penahan.

4) cara injeksi.

\section{Analisis Kesetabilan Lereng Friction Circle Method}

Metode yang diterapkan untuk analisis kestabilan lereng sudah banyak dibuat orang, salah satunya adalah analisis stabilitas lereng menggunakan Friction Circle Method. Untuk tanah kohesif, tahanan geser sepanjang bidang longsor tidak bergantung pada tegangan normal pada bidang tersebut. Jadi dengan mengambil momen terhadap pusat lingkaran, dapat dievaluasi stabilitasnya. Jika tanah mempunyai $\varnothing$ komponen gaya normal mempengaruhi distribusi tegangan gesernya. Pada bidang longsor, tegangan normal yang bekerja tidak merata, akan tetapi merupakan fungsi dari besarnya sudut pusat lingkaran $(\phi)$

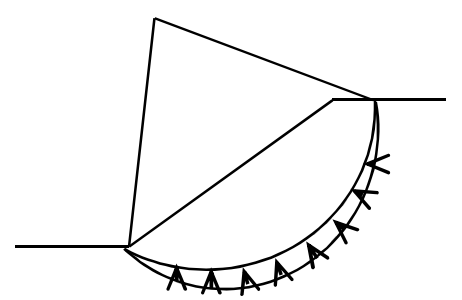

Gambar 1. Distribusi Tegangan Normal Pada Bidang Longsor

Tegangan geser sembarang titik pada bidang longsor dinyatakan dengan persamaan Mohr - Coulomb:

$$
F=\frac{s}{\tau}
$$

Kekuatan geser material yang tersedia untuk menahan material sehingga lereng tidak longsor dinyatakan dalam kriteria keruntuhan MohrColoumb sebagai berikut:

$$
\tau=c+\sigma \tan \varnothing
$$

dengan: 


$$
\begin{aligned}
& \tau=\text { Tegangan geser } \\
& \mathrm{c}=\text { kohesi } \\
& \varnothing=\text { sudut geser }
\end{aligned}
$$

\section{Kohesi dan Sudut Geser Dalam}

Kohesi adalah gaya tarik menarik antara partikel dalam tanah, dinyatakan dalam satuan berat per satuan luas. Kohesi , tanah akan semakin besar jika kekuatan gesernya makin besar. Nilai kohesi (c) diperoleh dari pengujian laboratorium yaitu pengujian kuat geser langsung (direct shear strength test) dan pengujian triaxial (triaxial test). Salah satu aspek yang memengaruhi nilai kohesi adalah kerapatan dan jarak antar molekul dalam suatu benda. Kohesi berbanding lurus dengan kerapatan suatu benda, sehingga bila kerapatan semakin besar maka kohesi yg akan didapatkan semakin besar. Dalam hal ini, benda berbentuk padat memiliki kohesi yang paling besar dan sebaliknya pada cairan (Bowles J.E. 1989).

Sudut geser dalam merupakan sudut yang dibentuk dari hubungan antara tegangan normal dan tegangan geser di dalam material tanah atau batuan. Sudut geser dalam adalah sudut rekahan yang dibentuk jika suatu material dikenai tegangan atau gaya terhadapnya yang melebihi tegangan gesernya. Semakin besar sudut geser dalam suatu material maka material tersebut akan lebih tahan menerima tegangan luar yang dikenakan terhadapnya (Bowles J.E. 1989).

Besaran nilai Sudut geser dalam (Ø) juga berkaitan dengan tingkat kepadatan suatu jenis tanah, yang dapat dilihat pada tabel 1 (Bowles J.E. 1989)

Tabel 1. Hubungan Tingkat Kepadatan dan Sudut Geser

\begin{tabular}{lc}
$\begin{array}{c}\text { Tingkat } \\
\text { Kepadatan }\end{array}$ & $\begin{array}{c}\text { Sudut Geser } \\
\text { Dalam }(\boldsymbol{\varnothing})\end{array}$ \\
\hline Sangat lepas & $<30$ \\
Lepas & $30-35$ \\
Agak Padat & $35-40$ \\
Padat & $40-45$ \\
Sangat Padat & $>45$ \\
\hline
\end{tabular}

Batas-batas nilai Sudut geser dalam (Ø) untuk beberapa jenis tanah dapat diperlihatkan dalam tabel 2 (Bowles J.E. 1989)

Tabel 2. Batas Nilai Sudut Geser dalam Tanah

\begin{tabular}{lll}
\hline \multicolumn{1}{c}{ Jenis Tanah } & \multicolumn{2}{l}{$\begin{array}{l}\text { Sudut geser dalam } \\
(\boldsymbol{\emptyset})^{\mathbf{0}}\end{array}$} \\
\cline { 2 - 3 } & Lepas & Padat \\
\hline Pasir bersudut & $32-36$ & $35-45$ \\
Pasir agak bersudut & $30-34$ & $34-40$ \\
Pasir bundar & $28-32$ & $32-38$ \\
Kerikil bersudut & $34-38$ & $40-50$ \\
Kerikil agak bersudut & $36-40$ & $38-42$ \\
Pasir berlanau & $25-35$ & $40-50$ \\
Lanau inorganic & & $30-36$ \\
Lempung & $13-22$ & $13-21$ \\
\hline
\end{tabular}

\section{Penelitian Terdahulu.}

Saputra S.A. (2017) dalam penelitiannya dengan judul " Analisis Stabilitas Lereng Dengan Perkuatan Dinding Penahan Tanah Kantilever Dan Geotekstil Pada Ruas Jalan Lintas LiwaSimpang Gunung Kemala KM. $268+550$, menganalisis stabilitas lereng tanpa perkuatan dan dengan perkuatan lereng. Penelitian dilakukan di ruas jalan di wilayah perbukitan TNBBS Lampung yang memiliki kondisi geografis terdiri dari tebing dan jurang yang cukup curam, sehingga rawan mengalami kelongsoran. Pada lereng tanpa perkuatan dengan nilai kohesi sebesar 3 $\mathrm{kPa}$ dan sudut geser tanah sebesar $38^{\circ}$, didapat angka keamanan sebesar 0,433 dan 0,4. Hasil tersebut membuktikan struktur lereng tidak aman, maka diperlukan solusi untuk penanganan kelongsoran. Hasil analisis stabilitas kelongsoran lereng yang diperkuat dengan kantilever didapat angka kemanan sebesar 1,852.

Hafez M (2015) dalam penelitiannya dengan judul "Analisa Pengaruh Kohesi dan Sudut Geser Dalam Terhadap Angka Keamanan Lereng" membahas tentang analisa 
pengaruh kohesi dan sudut geser terhadap perubahan angka keamanan lereng. Perhitungan dilakukan dengan dua cara, yaitu perhitungan secara manual dan perhitungan secara numeric dengan program GeoStudio 2007 Slope/W. Dalam penelitiannya, Hafez M menggunakan nilai kohesi antara 0 $\mathrm{kN} / \mathrm{m} 2$ sampai $200 \mathrm{kN} / \mathrm{m} 2$, dan nilai sudut geser dari $0^{0}$ sampai $55^{\circ}$. Hasil penelitian menunjukkan bahwa nilai factor keamanan lereng akan meningkat seiring dengan bertambahnya nilai kohesi dan sudut geser tanah.

Permana G.W. (2016) dengan studi kasus pada ruas jalan Liwa - Simpang Gunung Kemala STA. 263+650, yang mana hujan deras mengakibatkan jalan tersebut mengalami kelongsoran dan mengikis sebagian bahu jalan. Untuk mengetahui factor keamanan lereng dilokasi tersebut yang dapat memodelkan sesuai dengan kondisi asli di lapangan agar terjadi kondisi pendekatan dalam hasil analisis dan memudahkan dalam memodelkan penangannya, dilakukan anlisis dengan menggunakan rumus manual dan program Plaxis.

Dari hasil penelitian, menunjukkan bahwa parameter tanah sangat berpengaruh terhadap stabilitas lereng. Kondisi lereng dengan kondisi jenuh sebagian memiliki stabilitas paling kecil dibandingkan dengan kondisi lainnya. Berdasarkan hasil analisis yang dilakukan pada kondisi sebelum penanganan didapat nilai deformasi $=$ $885 \times 10-3 \mathrm{~m}$; active pore pressure = $168,89 \mathrm{~m}$; tegangan efektif tanah $=-$ $553,76 \mathrm{kN} / \mathrm{m} 2$; factor aman $=0,2847$. Pada kondisi setelah penanganan didapat nilai nilai deformasi $=818 \times 10-3 \mathrm{~m}$; actice pore pressure $=-132,36 \mathrm{~m}$; tegangan efektif tanah $=-209,77 \mathrm{kN} / \mathrm{m} 2$; factor aman $=1,354$.
Zainuri, dkk (2016) melakukan penelitian yang bersifat kuantitatif menggunakan metode Simplified Bishop. Hasil analisis data didapat karakteristik tanah dan bidang gelincir dengan Karakteristik tanah pembentuk tebing diperoleh kadar air 21,76\%; berat volume $(\gamma) \quad 1,89 \mathrm{gram} / \mathrm{cm}^{3}$; derajat kejenuhan $76,43 \%$; porositas $37,85 \%$; angka pori (e) $0,0609 \%$; Liquid Limit 27,825\%; Plastis Limit 23,090\%; Index Plastisitas $4,735 \%$; sudut geser $(\phi)$ 43,74 ${ }^{\circ}$; kohesi (c) $0,285 \mathrm{~kg} / \mathrm{cm}^{2}$; berat jenis 2,58; lanau $1,353 \%$; pasir $98,647 \%$; kerikil 0\% dan klasifikasi USCS adalah SP. Bidang gelincir untuk tebing berbentuk busur dengan jari-jari (R) 20 meter dan nilai faktor keamanan (Fs) sebesar 1,35 mendekati nilai yang diisyaratkan 1,2.

\section{METODE PENELITIAN}

1. Lokasi Penelitian.

Lokasi penelitian ditempatkan pada akses gerbang selatan Universitas Lancang Kuning, tebing sisi timur badan jalan antara hall olah raga Politeknik Caltex Riau dengan pos Waradipa mahasiswa Universitas Lancang Kuning

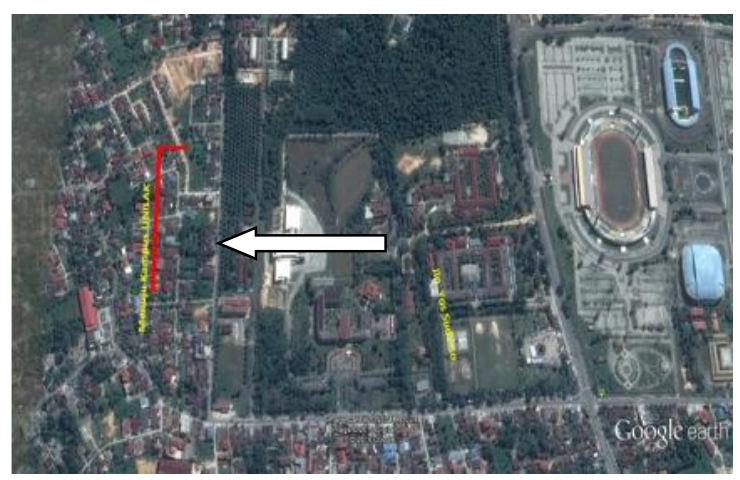

Gambar 2. Lokasi Penelitian

\section{Data dan Analisis Data}

a. Data

Data yang dipergunakan adalah parameter nilai kohesi (c), sudut geser tanah $(\varnothing$ dan berat isi 
tanah $(\gamma)$ yang telah didapat pada penelitian sebelumnya, yaitu penelitian tentang Nilai Kohesi dan Sudut Geser Tanah pada Akses Gerbang Selatan Universitas Lancang Kuning yang dilakukan oleh Haris VT dkk (2017), hasil penelitian ditampilkan pada tabel 3 di bawah ini, serta data kemiringan eksisting lereng badan jalan akses gerbang selatan Universitas Lancang Kuning yang langsung diukur dilapangan

Tabel 3. Hubungan Kedalaman, Nilai Kohesi, Sudut geser dan Berat isi

\begin{tabular}{cccc}
\hline $\begin{array}{c}\text { Kedalaman } \\
\text { sampel } \\
(\mathbf{m})\end{array}$ & $\begin{array}{c}\text { Kohesi } \\
\left(\mathbf{k g} / \mathbf{c m}^{2}\right)\end{array}$ & $\begin{array}{c}\text { Sudut } \\
\text { geser } \\
\left(\mathbf{\emptyset}^{\mathbf{0}}\right)\end{array}$ & $\begin{array}{c}\text { Berat } \\
\text { isi } \\
\left(\mathbf{g r} / \mathbf{c m}^{\mathbf{3}}\right)\end{array}$ \\
\hline 1 & 0,183 & 23,5 & 1,15 \\
2 & 0,11 & 25,29 & 1,14 \\
3 & 0,342 & 28,17 & 1,19 \\
3,5 & 0,25 & 29,71 & 1,21 \\
Rata-rata & 0,22 & 24,42 & 1,17 \\
\hline
\end{tabular}

b. Analisis data

Resultan tegangan normal dan komponen gesekan membuat sudut $\varnothing$ dengan arah garis normal. Garis yang ditarik lewat resultan kedua gaya ini akan berimpit dengan garis singgung lingkaran yang berjari-jari $R \sin \varnothing$ yang berpusat di $O$. Lingkaran ini disebut lingkaran $\varnothing$ $(\varnothing$ - circle) yang jari - jari lingkaran sebenarnya adalah lebih besar dari $\mathrm{R}$ $\sin \varnothing$.

Gambar 3. Menunjukkan lingkaran $\mathrm{AD}$ adalah bidang longsor yang dicoba lewat kaki lereng. Lingkaran bidang longsor berpusat di titik $\mathrm{O}$ berjari-jari $\mathrm{R}$

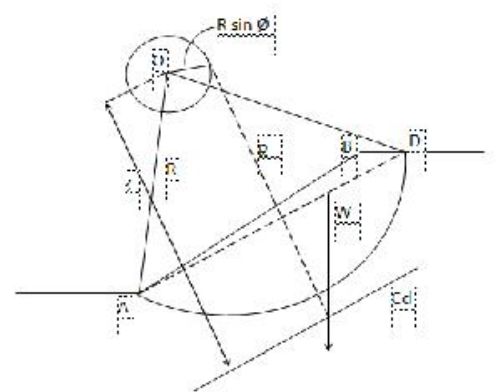

Gambar 3.Analisis Stabilitas Lereng Tanah dengan $\varnothing>0$

Gaya-gaya yang bekerja pada massa tanah yang akan longsor per meter tegak lurus bidang gambar adalah:

1) Gaya berat $\mathrm{W}=$ luas (ABD) $\mathrm{x}$ Berat isi $\mathrm{x} 1$

2) Kohesi sepanjang bidang longsor adalah $\mathrm{Cd}=\mathrm{cd} \mathrm{x}$ (panjang garis lurus $\mathrm{AD}$ ). Besaran cd adalah tahanan geser dari komponen kohesi, resultan gaya $\mathrm{Cd}$ sejajar garis $\mathrm{AB}$ dan berjarak $\mathrm{z}$ dari $\mathrm{O}$. Besarnya $\mathrm{z}=\mathrm{R} \times$ (panjang lengkung $\mathrm{AD}) /($ panjang garis lurus AD)

3) Resultan gaya normal dan gaya gesek sepanjang lengkung $\mathrm{AD}$, sebesar $\mathrm{P}$ dan membuat sudut $\varnothing$ terhadap arah garis normal pada lengkung AD. Untuk keseimbangan gaya $\mathrm{P}$ harus lewat titik dimana $\mathrm{W}$ dan $\mathrm{Cd}$ berpotongan. Arah gaya $\mathrm{P}$ merupakan garis singgung pada lingkaran- $\varnothing$. Karena arah gaya $\mathrm{Cd}$, $\mathrm{P}$ dan $\mathrm{W}$ telah diketahui, polygon gaya dapat dibuat. Besaran $\mathrm{Cd}$ diperoleh dari polygon gaya tersebut, kohesi yang dibutuhkan untuk keseimbangan (cd) adalah:

$\mathrm{cd}=\mathrm{Cd} /$ panjang garis $\mathrm{AD}$.

Factor aman terhadap kohesi $(\mathrm{Fc})$ $=\mathrm{c} / \mathrm{cd}$ dan $\mathrm{F} \varnothing=\operatorname{tg} \varnothing / \operatorname{tg} \varnothing_{\mathrm{i}}$

4) Untuk mendapatkan faktor aman sebenarnya, dianggap faktor aman terhadap kohesi dan gesekan sama, untuk itu perlu diulangi perhitungan dengan sudut gesek $\varnothing$ yang berbeda. Dengan menghubungkan $\mathrm{F} \varnothing=\mathrm{Fc}$, 
diperoleh perpotongan dua kurva dititik F sebagai faktor aman yang dimaksud

\section{HASIL DAN PEMBAHASAN \\ 1. Data-data Lapangan}

Dari pengukuran langsung dilapangan terhadap kondisi eksisting lereng badan jalan akses gerbang selatan Universitas Lancang Kuning pada daerah pengambilan data-data tanah sebelumnya, dapat digambarkan potongan melintang dan dimensinya sebagai

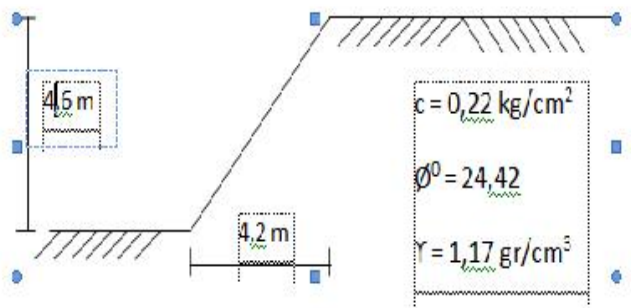

Gambar 4. Lereng Badan Jalan Akses

\section{Analisis Stabilitas Lereng}

Analisis stabilitas lereng dilakukan dengan menggunakan Friction Circle Method sebagai berikut:

Sudut AOD $=68,74^{\circ}=1,2$ radian dan jari-jari lingkaran $R=9,814 \mathrm{~m}$, sehingga dapat dihitung lengkung $\mathrm{AD}=1,2 \mathrm{x}$ $9,814=11,7607 \mathrm{~m}$, panjang garis $\mathrm{AD}=$ $11,0695 \mathrm{~m}$

Luas $\mathrm{ABD}=13,4973 \mathrm{~m} 2$. Berat tanah $\mathrm{ABD}(\mathrm{W})$ per $1 \mathrm{~m}$ lebar $=13,4973 \times 1,17$ $=15,7918$ ton.

Gaya Cd yang bekerja // garis $\mathrm{AD}$ pada jarak $\mathrm{z}$ dari $\mathrm{O}$ :

$\mathrm{Z}=9,8137 \times(11,7607 / 11,0695)=$ $10,4265 \mathrm{~m}$

Kemudian tentukan titik berat dari luasan ABD.

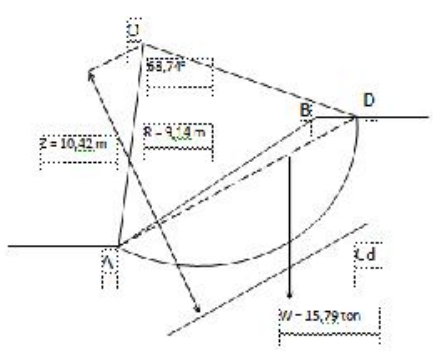

Gambar 5. Analisa Berat Tanah Pada Lereng

Selanjutnya gambarkan lingkaran $\varnothing$ dengan pusat di $\mathrm{O}$, dengan jari-jari :

$\mathrm{R} 1=9,8137 \sin 24,24=4,057 \mathrm{~m}$

Dari perpotongan gaya $\mathrm{W}$ dan $\mathrm{Cd}$, gambarkan garis singgung (p) ke lingkaran $\varnothing$. Garis ini merupakan arah dari resultan gaya akibat gaya normal dan gaya gesek pada permukaan AD.

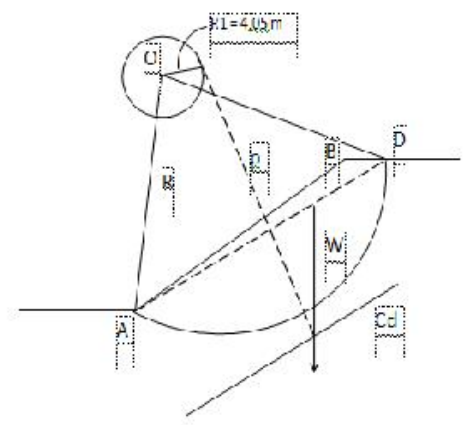

Gambar 6. Analisis Resultan Gaya Akibat Gaya Normal dan Gaya Gesek

Kemudian gambarkan segitiga gaya dengan skala tertentu antara $\mathrm{W}$, Cd dan p. Dari segitiga tersebut diperoleh $\mathrm{Cd}=1,7866$. Kohesi satuan yang terjadi = $1,7866 / 11,0695=0,1614$, maka faktor aman terhadap kohesi = $0,22 / 0,1614=1,363$. 


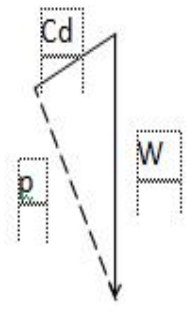

Gambar 7.Segitiga Gaya antara W,Cd dan $\mathrm{p}$

Untuk mendapatkan faktor aman sebenarnya, dianggap faktor aman terhadap kohesi dan geser sama, untuk itu ulangi perhitungan diatas dengan tiga sudut geser yang berbeda, tabel 4

Tabel 4. Besaran Tiga Sudut Geser Berbeda

\begin{tabular}{ccc}
\hline $\mathbf{n}$ & $\boldsymbol{\emptyset n}$ & $\mathbf{R n}=\mathbf{R}$ Sin $\boldsymbol{~} \mathbf{n}$ \\
\hline $\mathbf{1}$ & 24,42 & 4,057 \\
$\mathbf{2}$ & 27,00 & 4,460 \\
$\mathbf{3}$ & 30,00 & 4,910 \\
\hline
\end{tabular}

Selanjutnya perhitungan untuk mendapatkan Faktor aman dapat ditabelkan pada tabel 5 dan digambarkan grafiknya pada gambar 8

Tabel 5. Perhitungan Faktor Aman dari Tiga Sudut Geser yang Berbeda.

\begin{tabular}{cccccc}
\hline $\boldsymbol{\emptyset}$ & $\mathbf{R} \operatorname{Sin} \boldsymbol{\emptyset} \mathbf{n}$ & $\mathbf{F} \boldsymbol{\emptyset}=\mathbf{t g} \boldsymbol{\emptyset} / \mathbf{t g} \boldsymbol{\emptyset}$ & $\mathbf{C d}$ & $\mathbf{C n}=\mathbf{C d} / \mathbf{A D}$ & $\mathbf{F c}=\mathbf{c} / \mathbf{c n}$ \\
\hline 24,42 & 4,06 & 1,00 & 3,60 & 0,33 & 0,68 \\
27,00 & 4,46 & 0,89 & 2,58 & 0,23 & 0,94 \\
30,00 & 4,91 & 0,79 & 1,79 & 0,16 & 1,36 \\
\hline
\end{tabular}

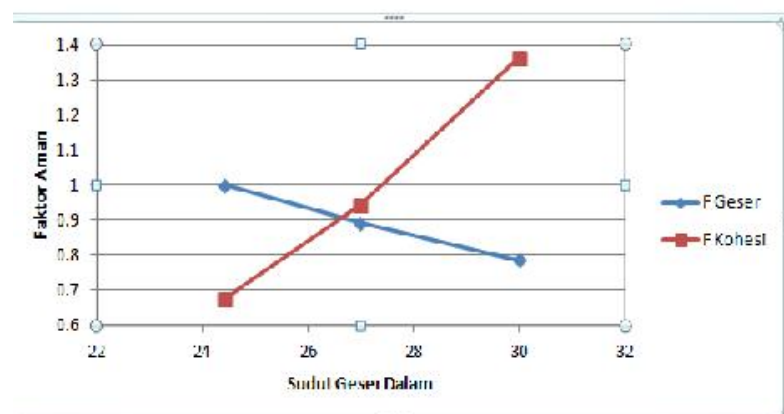

Gambar 8. Grafik Hubungan antara F geser dan F Kohesi

Dengan menghubungkan $\mathrm{F}$ Geser $(\mathrm{F} \varnothing)$ dan $\mathrm{F}$ Kohesi $(\mathrm{Fc})$, diperoleh perpotongan dua kurva dititik $\mathrm{F}=0,91$. Dengan demikian faktor aman untuk kesetabilan lereng akses gerbang selatan Universitas Lancang Kuning adalah sebesar 0,91 .

\section{E. KESIMPULAN}

Dari hasil penelitian dan perhitungan yang dilakukan, didapat besaran faktor aman untuk kesetabilan lereng akses gerbang selatan Universitas Lancang Kuning adalah sebesar 0,91.
Faktor aman ini lebih kecil dari 1, sehingga dapat disimpulkan bahwa kondisi lereng akses gerbang selatan Universitas Lancang Kuning dalam keadaan tidak aman.

\section{DAFTAR PUSTAKA}

Bowles J.E. (1989). Sifat-sifat Fisis dan Geoteknis Tanah. Penerbit Erlangga Jakarta.

Hafez M . (2015), Analisa Pengaruh Kohesi dan Sudut Geser Dalam Terhadap Angka Keamanan Lereng, 
Diploma Thesis Universitas Andalas.

Haris, V. T., Lubis, F., \& Winayati, W. (2018). "Nilai Kohesi Dan Sudut Geser Tanah Pada Akses Gerbang Selatan Universitas Lancang Kuning”. Siklus : Jurnal Teknik Sipil, 4(2), 123-130. https://doi.org/10.31849/siklus.v4i2 .1143

Kusuma D. (2016). "Kestabilan Lereng Terhadap Bahaya Longsor". 12 Desember 2017. http://dwikusumadpu.wordp

Permana G.W. (2016). "Analisis Stabilitas Lereng dan Penanganan Longsoran Menggunakan Metode Elemen Hingga Plaxis V.8.2 (Studi Kasus: Ruas Jalan Liwa - Simpang Gunung Kemala STA.263+650)". Skripsi Jurusan Teknik Sipil Fakultas Teknik Universitas Lampung. Bandar Lampung.
Saputra S.A. (2017) “Analisis Stabilitas Lereng Dengan Perkuatan Dinding Penahan Tanah Kantilever Dan Geotekstil Pada Ruas Jalan Lintas Liwa-Simpang Gunung Kemala KM. 268+550." Skripsi Jurusan Teknik Sipil Fakultas Teknik Universitas Lampung. Bandar Lampung.

Zainuri, Z., Yanti, G., \& Megasari, S. W. (2016). "Analisis Karakteristik Tanah Dan Stabilitas Lereng Fakultas Ekonomi Universitas Lancang Kuning”. Siklus : Jurnal Teknik Sipil, 2(2), p 125-134, doi.org/10.31849/siklus.v2i2.357

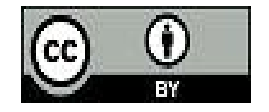

(C) 2019 Siklus Jurnal Teknik Sipil All rights reserved. This is an open access article distributed under the terms of the CC BY License (http://creativecommons.org/licenses/by/4.0/) 